\title{
Application of a Fuzzy Inference System for the Optimization of Material Removal Rate and Multiple Surface Roughness Characteristics in the Machining of GFRP Polyester Composites
}

\author{
Ankita Singh*, Saurav Datta**, Siba Sankar Mahapatra***
}

\begin{abstract}
This paper presents a multi-objective extended optimization methodology applied in the machining of a randomly oriented GFRP rod. Design of Experiment (DOE) has been selected based on a L9 orthogonal array design with varying process control parameters like: spindle speed, feed rate and depth of cut. Multiple surface roughness parameters of the machined FRP product along with the Material Removal Rate (MRR) of the machining process have been optimized simultaneously. The Fuzzy Inference System (FIS) has been proposed for providing feasible means for the meaningful aggregation of multiple objective functions into an equivalent single performance index (MPCI). This Multi-Performance Characteristic Index (MPCI) has been optimized using the Taguchi method. The approach adapted here is capable of overcoming limitations/ assumptions of existing optimization methodologies available in the literature.
\end{abstract}

Keywords: GFRP; DOE; the Fuzzy Inference System (FIS); the Taguchi method

Mathematics Subject Classification: 62C86; $62 \mathrm{~K} 86$

Revised: October 22, 2013

\section{INTRODUCTION AND PRIOR STATE OF THE ART}

A Fiber Reinforced Polymer (FRP) composite is defined as a polymer (plastic) matrix, either thermoset or thermoplastic, that is reinforced (combined) with a fiber or other reinforcing material with a sufficient aspect ratio (length to thickness) to provide a discernable reinforcing function in one or more directions. FRP composites are different from traditional construction materials such as steel or aluminum. FRP composites are anisotropic (properties apparent in the direction of the applied load) whereas steel or aluminum is isotropic (uniform properties in all directions, independent of the applied load). Therefore, FRP composite properties are directional, meaning that the best mechanical properties are in the direction of the fiber placement. Composites are similar to reinforced concrete where the rebar is embedded in an isotropic matrix called

* Department of Mechanical Engineering National Institute of Technology, Rourkela-769008, e-mail: ankitas836@gmail.com

** e-mail: sdattaju@gmail.com

*** e-mail: mahapatrass2003@gmail.com, corresponding author 
concrete. Composites are composed of: resins, reinforcements, fillers and additives. The primary functions of the resin are to transfer stress between the reinforcing fibers, act as a glue to hold the fibers together, and protect the fibers from mechanical and environmental damage. The most common resins used in the production of FRP grating are polyesters (including orthophthalic-" ortho" and isophthalic-" iso"), vinyl esters and phenolics. The primary function of fibers or reinforcements is to carry a load along the length of the fiber to provide strength and stiffness in one direction. Reinforcements can be oriented to provide tailored properties in the direction of the loads imparted on the end product. The largest volume reinforcement is glass fiber. Fillers are used to improve performance and reduce the cost of a composite by lowering the compound cost of the significantly more expensive resin and imparting benefits such as shrinkage control, surface smoothness, and crack resistance. Additives and modifier ingredients expand the usefulness of polymers, enhance their processability or extend product durability.

The machining of Polymer Composites is an indispensable interdisciplinary relevance for process design, tool and production engineers in composite manufacturing. A number of papers are available related to the growth of theory and practices on various aspects of composite machining. The literature reveals that aspects of composite machining belong to a wide field with inter-disciplinary, multi-criteria decision-making complexity, and designing a framework has always been a challenging issue. Four basic trends in research on machining and the machinability of composites, highlighted in literature are as follows (Jamal, 2009):

a) The mechanics of chip formation and the critical influence of composite architecture on chip formation mode, cutting forces and surface quality

b) The phenomena of tool wear and an analysis of tool materials and tool wear mechanisms in the machining of FRP composites

c) The machinability of FRP composites by traditional and nontraditional methods including turning, milling, drilling, abrasive, abrasive water jet and laser machining

d) The issue of health and safety in machining FRP composites

Santhanakrishnam et al. (1988) carried out face turning on glass fiber reinforced plastics (GFRP), carbon fiber reinforced plastics (CFRP) and kevlar fiber reinforced plastics (KFRP) cylindrical tubes and studied their machined surfaces for possible application as friction surfaces. The mechanisms of material removal, tool wear, cutting forces were also discussed. El-Sonbaty et al. (2004) investigated the influence of cutting speed, feed, drill size and fiber volume fraction on the thrust force, torque and surface roughness in the drilling processes of fiber-reinforced composite materials. Davim and Mata (2005a) optimized surface roughness in turning FRPs tubes manufacturing by filament winding and hand lay-up, using polycrystalline diamond cutting tools. Additionally, the optimal material removal rates have been obtained through multiple analysis regression (MRA). Mohan et al. (2005) applied Taguchi optimization methodology to optimize cutting parameters in the drilling of glass fiber reinforced composite (GFRC) material. The drilling parameters and specimen parameters evaluated were speed, feed rate, drill size and specimen thickness. In another paper, Davim and Mata (2005b) studied machinability in the turning 
processes of fiber reinforced plastics (FRPs) using polycrystalline diamond cutting tools. A statistical technique, using orthogonal arrays and an analysis of variance, was employed to investigate the influence of cutting parameters on specific cutting pressure and surface roughness. The objective was to evaluate the machinability of these materials as a function of the manufacturing process (filament winding and hand lay-up). A new machinability index was also proposed by the authors.

Jawali et al. (2006) fabricated a series of short glass fiber-reinforced nylon 6 composites with different weight ratios of glass content viz., 15, 30, 40, and $50 \%$ by melt mixing. The fabricated nylon 6 composites have been characterized for physicmechanical properties such as specific gravity, tensile properties, and wear resistance. A marginal improvement in tensile strength and tensile modulus was observed with an increase in high modulus fiber. Wear resistance was found to be increased with the increase in rigid glass fiber content in the nylon matrix. The dimensional stability of the composite was improved with the increase in fiber content. Bagci and Işık (2006) carried out orthogonal cutting tests on unidirectional glass fiber reinforced plastics (GFRP), using cermet tools. An artificial neural network (ANN) and response surface (RS) model were developed to predict surface roughness on the turned part surface. Palanikumar et al. (2006) assessed the influence of machining parameters on the machining of GFRP composites using coated cermet tool inserts. The factors considered were cutting speed, work piece fiber orientation angle, depth of cut and feed rate. A procedure was developed to assess and optimize the chosen factors to attain minimum surface roughness by incorporating: (i) response table and response graph; (ii) normal probability plot; (iii) interaction graphs; (iv) Analysis of Variance (ANOVA) technique. Davim and Mata (2007) investigated the machinability in the turning processes of glass fiber reinforced plastics (GFRPs) manufactured by a hand lay-up. A statistical technique, using orthogonal arrays and analysis of variance (ANOVA), was employed to know the influence of cutting parameters on specific cutting pressure and surface roughness. The objective was to evaluate the machinability of these materials in the function of a cutting tool (polycrystalline diamond and cemented carbide tools).

Palanikumar and Davim (2007) developed a mathematical model to predict the tool wear on the machining of GFRP composites using regression analysis and analysis of variance (ANOVA) in order to study the main and interaction effects of machining parameters, viz., cutting speed, feed rate, depth of cut and work piece fiber orientation angle. In another work Palanikumar (2007) attempted to model the surface roughness through the response surface method (RSM) in machining GFRP composites. Karnik et al. (2008) applied the artificial neural network (ANN) model to study the machinability aspects of unreinforced polyetheretherketone (PEEK), reinforced polyetheretherketone with $30 \%$ of carbon fibers (PEEK CF 30) and 30\% of glass fibers (PEEK GF 30) machining. A multilayer feed forward ANN was employed to study the effect of parameters such as tool material, work material, cutting speed and feed rate on two aspects of machinability, namely, power and specific cutting pressure. The investigation results showed that, K10 tool provides better machinability for PEEK and PEEK CF 30 materials, while PCD tool was preferred for PEEK GF 30 material. Palanikumar et al. (2008) highlighted the use of Taguchi and response surface methodologies for minimizing the surface roughness in machining glass fiber reinforced (GFRP) 
plastics with a polycrystalline diamond (PCD) tool. The cutting parameters used were cutting speed, feed and depth of cut. The effect of cutting parameters on surface roughness was evaluated and the optimum cutting condition for minimizing the surface roughness was determined. A second-order model was established between the cutting parameters and surface roughness using response surface methodology. Basheer et al. (2008) presented an experimental work on the analysis of machined surface quality on $\mathrm{Al} / \mathrm{SiCp}$ composites leading to an artificial neural network-based (ANN) model to predict the surface roughness. Palanikumar et al. (2008) studied the influence of cutting parameters on surface roughness parameters such as $R_{a}, R_{t}, R_{q}, R_{p}$ and $R_{3 z}$ in the turning of glass fiber reinforced composite materials. Empirical models were developed to correlate the machining parameters with surface roughness.

Davim et al. (2009) provides the better understanding of the machinability of PA 66 polyamide with and without $30 \%$ glass fiber reinforcing, when precision turning at different feed rates and using four distinct tool materials. The findings indicated that the radial force component presented the highest values, followed by the cutting and feed forces. The PCD tool gave the lowest force values associated with best surface finish, followed by the ISO grade K15 uncoated carbide tool with a chip breaker when machining reinforced polyamide. Continuous coiled micro-chips were produced, irrespectively of the cutting parameters and tool material employed. In another reporting, Palanikumar and Davim (2009) assessed the factors influencing tool wear on the machining of GFRP composites and optimized the chosen factors to attain minimum tool wear. The factors considered were cutting speed, fiber orientation angle, depth of cut and feed rate. Sait et al. (2008) presented a new approach for optimizing the machining parameters on turning glass-fiber reinforced plastic (GFRP) pipes. Optimization of machining parameters was done by an analysis called desirability function analysis, which was found to be a useful tool for optimizing multi-response problems. Based on Taguchi's L18 orthogonal array, turning experiments were conducted for filament wound and hand layup GFRP pipes using a K20 grade cemented carbide cutting tool. The machining parameters such as cutting velocity, feed rate and depth of cut were optimized by multi-response considerations, namely surface roughness, flank wear, crater wear and machining force. A composite desirability value was obtained for the multi-responses using individual desirability values from the desirability function analysis. Based on the composite desirability value, the optimum levels of parameters were identified.

With the increasing use of fiber reinforced plastic (FRP) composites outside the defense, space and aerospace industries, the machining of these materials is gradually assuming a significant role. The current knowledge of machining FRP composites is in a transition phase for its optimum economic utilization in various fields of applications. Therefore, material properties and theoretical mechanics have become the predominant research areas in this field. With increasing applications, economical techniques of production are indeed very important to achieve fully automated large-scale manufacturing cycles. Although FRP composites are usually moulded, for obtaining close fits and tolerances and also achieving near-net shape, a certain amount of machining has to be carried out. Due to their anisotropy, and non-homogeneity, FRP composites face considerable problems in machining like fiber pull-out, delamination, burning, 
etc. There is a remarkable difference between the machining of conventional metals and their alloys and that of composite materials. Further, each composite differs in its machining behavior since its physical and mechanical properties depend largely on the type of fiber, the fiber content, the fiber orientation and variations in the matrix material. A considerable amount of literature has been found readily available on the machinability of (Glass Fiber Reinforced Plastic) GFRP composites; with a very limited work on process optimization of FRP composites. It is felt that the optimization of machining parameters for FRP composites is still an emerging area of research.

The literature highlights that extensive efforts have been rendered by previous investigators on various aspects of composite machining. Machinability aspects on a wide variety of FRP composites with different cutting tool materials have been mostly investigated in various machining operations like: turning, drilling, milling etc. Effort has been made to study the influence of controllable process parameters on various aspects of machining performance like: tool wear, cutting forces, surface roughness, delamination etc. Mathematical models have also been developed to understand the functional relationship among process parameters with the aforesaid process responses. The effects of process parameters on flank, crater wear, various cutting forces (cutting force, feed force etc.) have been studied in detail. Roughness modeling has been reported extensively and well documented in the literature; but mostly it is based on centre line roughness average $\left(R_{a}\right)$. But surface quality/ integrity consists of so many statistical measures like: $R_{z}, R_{k u}, R_{s m}, R_{z 1 \max }, R_{s k}$ (Sahoo, 2005) which need to be investigated in detail for a better understanding of the machining process behavior on composites. There exists scope for optimizing aforesaid multiple surface-roughness features to achieve desired surface finish. Apart from tool life-tool wear, cutting force and surface roughness; another aspect of machining operation is material removal rate (MRR) which is indirectly related to productivity. There must be an optimal compatible balance between quality and productivity.

Optimization aspects of composite machining have been highlighted in the literature, but to a limited extent. In most of the cases optimization has been done on a single objective function. But in practice, it has been found that optimizing one response may not be favorable for other response(s) on that particular optimal parameter setting. This invites a multi-objective optimization problem in order to optimize multiple objective functions (may be contradicting in nature with respect to other) simultaneously.

The literature highlights that the Taguchi method is very popular in product/process optimization as it requires a well balanced experimental design (a limited number of experiments) which saves experimental time as well as cost. Not only this, Taguchi's approach finds optimal at discrete levels of the process parameters; which can easily be adjusted in the machine/setup. But this method fails to solve multi-objective optimization problems. In order to overcome this, desirability function approach (Sait et al., 2008), utility theory (Kumar et al., 2000; Walia et al., 2006), grey relation theory (Datta et al., 2008), have been applied by previous investigators in combination with the Taguchi method. The purpose is to aggregate multiple responses (objective functions) into an equivalent quality index (single objective function) which can easily be optimized using the Taguchi method. 
In this aggregation procedure, individual priority weights are required to be assigned to different responses. In practice, these responses may not be equally important. Degree of importance/ priority of various responses depend on application area and functional requirements of the product. Assignment of response priority weights basically depends on the discretion of the decision maker. Change in value of the priority weights yield change in the value of the aggregated quality index. In this context the entropy measurement technique has been documented by (Datta et al., 2009a) for the computation of response priority weights. The method not only brings computational complexity but also seems unreliable in the narrow response domain.

Moreover, the aforesaid approaches are based on the assumption that responses are uncorrelated. Interdependence of the responses has been assumed negligible; while in practice any change in one response remarkably affects another response. Thus, the assumption of negligible response correlation may create imprecision, uncertainty as well as vagueness in the solution. To solve the inter-correlation problem, the Principal Component Analysis (PCA) may be a useful statistical technique for examining the relationships within a given data set of multiple-performance-characteristics. A new set of uncorrelated data, called principal components (PCs) can be derived by PCA in descending order of their ability to explain the variance of the original dataset. But, when more than one individual PCs show considerable accountability proportion; the aggregation of PCs is difficult (Datta et al., 2009b; Routara et al., 2010). To overcome this the Weighted Principal Component Analysis (WPCA) has been proposed by (Liao, 2006). It is based on the assumption that the accountability proportion is to be treated as individual response weights. It is, therefore, indeed required to develop such a model which can efficiently avoid as well as overcome various drawbacks/ assumptions of aforesaid optimization methodologies. In this context, a fuzzy expert system (Lu, 2007; Zadeh, 1976; Mendel, 1995; Cox, 1992; Yager, 1999) combined with the Taguchi method has been proposed.

\section{EXPERIMENTATION AND DATA COLLECTION}

\subsection{WORK MATERIAL}

Glass Fiber Reinforced Polyester (GFRP) composite has been selected as work piece material. The specifications of the work piece material are shown in Table 1.

Table 1. Specifications of work material

\begin{tabular}{|l|l|}
\hline Resin used & Polyester resin \\
\hline Fiber orientation & Random \\
\hline Method of preparation & The hand molding method \\
\hline Composition & $75: 25$ (Resin: Fiber) \\
\hline Weight percentage of hardener & $5 \%$ \\
\hline Density & $2 \mathrm{gm} / \mathrm{cm}^{3}$ \\
\hline
\end{tabular}




\subsection{CUTTING TOOL USED}

Carbide tools have been found to perform better than high speed steel. So, a single point carbide tool has been used for this investigation.

\subsection{DESIGN OF EXPERIMENT (DOE)}

In the present study, spindle speed $(\mathrm{N}, \mathrm{rpm})$, feed rate (f, $\mathrm{mm} / \mathrm{min}$ ) and depth of cut $(\mathrm{d}, \mathrm{mm})$, have been selected as design factors while other parameters have been assumed to be constant over the experimental domain. The process variables (design factors) with their values at different levels have been listed in Table 2 . It is known that the selection of the values of the variables is limited by the capacity of the machine used in the experimentation as well as the recommended specifications for different work piece and tool material combinations. Therefore, three levels have been selected for each of the aforesaid three factors. In the present investigation, the $\mathrm{L}_{9}$ Orthogonal Array (OA) design has been considered for experimentation (Tab. 3). The interaction effect of process parameters have been assumed negligible.

Table 2. Process parameters and domain of experiment

\begin{tabular}{|c|l|c|l|c|c|c|}
\hline Sl. No. & Process parameters & Notation & Unit & Level 1 & Level 2 & Level 3 \\
\hline 1 & Cutting speed & $\mathrm{N}$ & RPM & 360 & 530 & 860 \\
\hline 2 & Feed rate & $\mathrm{f}$ & $\mathrm{mm} / \mathrm{rev}$ & 0.083 & 0.166 & 0.331 \\
\hline 3 & Depth of cut & $\mathrm{d}$ & $\mathrm{mm}$ & 3.0 & 4.0 & 5.0 \\
\hline
\end{tabular}

Table 3. Taguchi's L9 orthogonal array design of experiment

\begin{tabular}{|c|c|c|c|}
\hline \multirow{2}{*}{ Sl. No. } & \multicolumn{3}{|c|}{ Factorial combination (Coded form) } \\
\cline { 2 - 4 } & $\mathrm{N}$ & $\mathrm{f}$ & $\mathrm{d}$ \\
\hline 1 & 1 & 1 & 1 \\
\hline 2 & 1 & 2 & 2 \\
\hline 3 & 1 & 3 & 3 \\
\hline 4 & 2 & 1 & 2 \\
\hline 5 & 2 & 2 & 3 \\
\hline 6 & 2 & 3 & 1 \\
\hline 7 & 3 & 1 & 3 \\
\hline 8 & 3 & 2 & 2 \\
\hline 9 & 3 & 3 & \\
\hline
\end{tabular}

\subsection{EQUIPMENT USED FOR EXPERIMENTATION AND DATA COLLECTION}

The machine used for turning is a PINACHO manually operated lathe. The surface roughness parameters have been measured using the stylus-type profilometer, Talysurf (Taylor Hobson, Surtronic 3+). The measured roughness parameters: $R_{q}, R_{a}, R_{t}$, 
$R_{k u}, R_{z}, R_{s m}$ along with the material removal rate (MRR) are shown in Table 4 . The definitions of various surface roughness features selected in the present study have been given in Appendix 2.

Table 4. Response data (various surface roughness parameters and MRR)

\begin{tabular}{|c|l|l|l|l|l|l|l|}
\hline Sl. No. & $\begin{array}{c}R_{q} \\
(\mu \mathrm{m})\end{array}$ & $\begin{array}{c}R_{a} \\
(\mu \mathrm{m})\end{array}$ & $\begin{array}{c}R_{t} \\
(\mu \mathrm{m})\end{array}$ & $\begin{array}{c}M R R \\
\left(\mathrm{~mm}^{3} / \mathrm{min}\right)\end{array}$ & $R_{k u}$ & $\begin{array}{c}R_{z} \\
(\mu \mathrm{m})\end{array}$ & $\begin{array}{c}R_{s m} \\
(\mathrm{~mm})\end{array}$ \\
\hline 1 & 4.14 & 3.375 & 24.25 & 2747.52 & 2.99 & 18.6 & 0.10065 \\
\hline 2 & 5.735 & 4.585 & 36.5 & 5615.76 & 3.995 & 25.75 & 0.133 \\
\hline 3 & 4.015 & 3.19 & 25.6 & 12352.9 & 4.35 & 18.45 & 0.10205 \\
\hline 4 & 3.43 & 2.685 & 21.45 & 4421.05 & 4.93 & 16.05 & 0.194 \\
\hline 5 & 4.58 & 3.56 & 28.1 & 10869.6 & 5.33 & 20.55 & 0.09605 \\
\hline 6 & 4.65 & 3.785 & 28.95 & 15245.9 & 3.565 & 20.75 & 0.1255 \\
\hline 7 & 5.595 & 4.55 & 35.4 & 6896.55 & 3.49 & 25.45 & 0.1145 \\
\hline 8 & 5.615 & 4.54 & 39.45 & 11797.8 & 5.215 & 24.85 & 0.1145 \\
\hline 9 & 3.18 & 2.515 & 19.4 & 26511.6 & 4.835 & 14.05 & 0.114 \\
\hline
\end{tabular}

\section{FUZZY INFERENCE SYSTEM (FIS)}

Fuzzy logic is a mathematical theory of inexact reasoning, which allows for the human reasoning process to be modeled in linguistic terms (Lu, 2007; Zadeh, 1976; Mendel, 1995; Cox, 1992; Yager, 1999). It is highly suitable for defining the relationship between system input and desired outputs. Fuzzy controllers and fuzzy reasoning have found particular applications in very complex industrial systems which cannot be modeled precisely even under a variety of assumptions and approximations. A fuzzy system is mainly composed of a fuzzifier, an inference engine, a database, a rule base and a defuzzifier. In the study, the fuzzifier first uses membership functions to convert the crisp input into fuzzy sets, and then the inference engine performs a fuzzy reasoning on fuzzy rules to generate fuzzy values. Then, the defuzzifier converts these values into crisp outputs. Fuzzy values are determined by the membership functions, which define the degree of membership of an object in a fuzzy set. However, so far there has been no standard method of choosing the proper shape of the membership functions for the fuzzy set of control variables. Trial and error methods are usually employed. On the basis of fuzzy rules, the Mamdani implication method is employed in this study for fuzzy inference reasoning. To obtain a rule:

$$
\begin{gathered}
R_{i}: \text { if } x_{1} \text { is } A_{i 1}, x_{2} \text { is } A_{i 2} \text {, and } x_{s} \text { is } A_{i M} \\
y_{i} \text { is } C_{i}
\end{gathered}
$$

Here $M$ is the total number of fuzzy rules. $x_{j}(j=1,2, \ldots, s)$ are the input variables, $y_{i}$ are the output variables and $A_{i j}$ and $C_{i}$ are fuzzy sets modeled by the membership functions $\mu_{A_{i j}}$ and $\mu_{C_{i}}$, respectively. Based on the Mamdani implication 
method of inference reasoning for a set of disjunctive rules, the aggregated output for the $M$ rules is (Zadeh, 1976):

$$
\mu_{C i}\left(y_{j}\right)=\max \left\{\min \left[\mu_{A i 1}\left(x_{1}\right), \mu_{A i 2}\left(x_{2}\right), \ldots, \mu_{A i s}\left(x_{s}\right)\right]\right\}, \quad i=1,2, \ldots, M
$$

Using a defuzzification method, fuzzy values can be combined into one single crisp output value. The centre of gravity, one of the most popular methods for defuzzifying fuzzy output functions, is employed in this study. The formula to find the centroid of the combined outputs is given by:

$$
\hat{y}_{i}=\frac{\int y_{i} \mu_{c i}\left(y_{i}\right) d y}{\int \mu_{c i}\left(y_{i}\right) d y}
$$

\section{THE TAGUCHI METHOD}

Dr. Genichi Taguchi in 1940s developed a new concept to optimize product/process for engineering experimentation. The concepts are:

- Quality should be designed into the product and not inspected into it.

- Quality is best achieved by minimizing the deviation from the target. It is immune to uncontrollable environmental factors.

- The cost of quality should be measured as a function of the deviation from the standard and the losses should be measured system- wide.

- It combines the experiment design theory and quadratic quality loss functions have been applied to the robust design of products and process. The Taguchi method uses a special design of orthogonal arrays to study the entire parameter space with a small number of experiments.

The change in quality characteristics of a product response to a factor introduced in the experimental design is the signal of the desired effect. The effect of the external factors of the outcome of the quality characteristic under test is termed as noise. To use the loss function as a figure of merit an appropriate loss function with its constant value must first be established which is not always cost effective and easy. The experiment results are then transformed into a Signal-to-Noise (S/N) ratio. Taguchi recommends the use of $\mathrm{S} / \mathrm{N}$ ratio to measure the quality characteristics deviating from the desired value. The $\mathrm{S} / \mathrm{N}$ ratio for each level of process parameters is computed based on the $\mathrm{S} / \mathrm{N}$ analysis and converted into a single metric. The aim in any experiment is to determine the highest possible $\mathrm{S} / \mathrm{N}$ ratio for the result irrespective of the type of the quality characteristics. A high value of $\mathrm{S} / \mathrm{N}$ implies that signal is much higher than the random effect of noise factors. In the Taguchi method of optimization, the $\mathrm{S} / \mathrm{N}$ ratio is used as the quality characteristic of choice.

The different $\mathrm{S} / \mathrm{N}$ ratio characteristics are given as:

1) Nominal-the-Best (NB)/Target-the-Best (TB),

2) Lower-the-Better (LB),

3) Higher-the-Better (HB). 


\subsection{NOMINAL-THE-BEST (NB)/ TARGET-THE-BEST (TB)}

In this approach, the closer to the target value, the better. It does not matter whether the deviation is above or below the target value. Under this approach the deviation is quadratic. The formula for these characteristics is:

$$
\frac{S}{N}=10 \log \frac{y}{S_{y}^{2}}
$$

The graph (Fig. 1) portrays nominal the best characteristics.

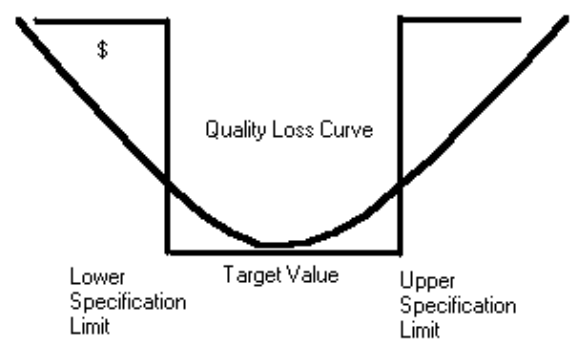

Fig. 1. Nominal-the-Best

\subsection{LOWER-THE-BETTER (LB)}

The smaller the better approach held when a company desires smaller values. As the value gets larger, the loss incurred grows. The formula for these characteristics is:

$$
\frac{S}{N}=-10 \log \frac{1}{n} \sum y^{2}
$$

The graph (Fig. 2) portrays Lower-the-Better characteristics.

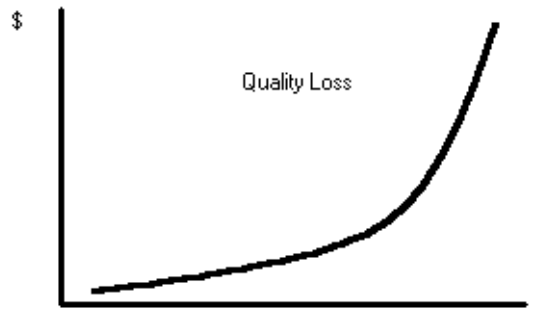

Quality Characterisitic

Fig. 2. Lower-the-Better 


\subsection{HIGHER-THE-BETTER (HB)}

Larger is better occurs when a company desires higher values of a characteristic. Two examples given are employee participation and the customer acceptance rate. Under this approach, the larger is the characteristic; the smaller is the quality loss function. The formula for these characteristics is:

$$
\frac{S}{N}=-10 \frac{1}{n} \sum \frac{1}{y^{2}}
$$

Here,

$y$ - average of observed values,

$S_{y}^{2}$ - variance of $y$,

$N$ - number of observations,

$y$ - observed data.

The graph (Fig. 3) portrays larger the better characteristics.

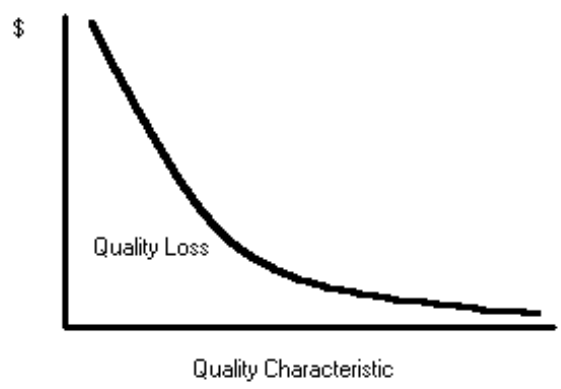

Fig. 3. Higher-the-Better

\section{DATA ANALYSIS: EVALUATION OF OPTIMAL PARAMETER SETTING}

Experimental data (corresponding to Table 4) have been normalized first. For all surface roughness parameters, a Lower-the-Better (LB) criterion and for MRR, a Higher-theBetter (HB) criterion has been selected. Normalized data has been furnished in Table 5.

The following equations have been explored for data normalization. The normalized data corresponding to Lower-the- Better (LB) criterion can be expressed as:

$$
x_{i}(k)=\frac{\max y_{i}(k)-y_{i}(k)}{\max y_{i}(k)-\min y_{i}(k)}
$$

For Higher-the-Better (HB) criterion, the normalized data can be expressed as:

$$
x_{i}(k)=\frac{y_{i}(k)-\min y_{i}(k)}{\max y_{i}(k)-\min y_{i}(k)}
$$




\begin{tabular}{|c|c|c|c|c|c|c|c|c|c|}
\hline 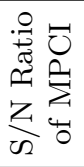 & $\begin{array}{l}\infty \\
\infty \\
\exists \\
\stackrel{1}{\phi}\end{array}$ & $\begin{array}{l}\dot{Q} \\
\stackrel{o}{0} \\
\dot{\varphi}\end{array}$ & $\begin{array}{l}0 \\
\stackrel{\leftrightarrow}{0} \\
0 \\
\dot{\varphi}\end{array}$ & 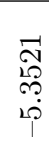 & 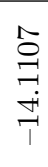 & $\begin{array}{l}\stackrel{8}{ } \\
\text { i⿱ } \\
\dot{\varphi}\end{array}$ & 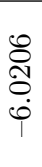 & $\begin{array}{l}\stackrel{0}{0} \\
\stackrel{\sim}{0} \\
0 \\
\dot{\varphi}\end{array}$ & $\begin{array}{l}0 \\
-9 \\
0 \\
10 \\
10 \\
1\end{array}$ \\
\hline $\begin{array}{l}\text { U } \\
\sum \\
\Sigma\end{array}$ & 足 & $\stackrel{10}{0}^{20}$ & $\stackrel{10}{0}$ & $\stackrel{\overrightarrow{L 1}}{0}$ & $\begin{array}{l}\sqrt{\sigma} \\
\stackrel{3}{0}\end{array}$ & $\stackrel{F}{\stackrel{F}{\circ}}$ & $\stackrel{10 \rho}{0}$ & $\ddot{10}$ & $\stackrel{n}{\stackrel{n}{0}}$ \\
\hline$\underset{\infty}{\tilde{\infty}}$ & 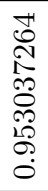 & 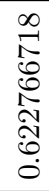 & 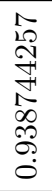 & 0 & - & 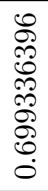 & $\begin{array}{l}\sigma \\
\sigma \\
\infty \\
\infty \\
00 \\
0 \\
\sigma \\
\infty \\
\infty \\
0\end{array}$ & $\begin{array}{l}\sigma \\
\sigma \\
\infty \\
\infty \\
0 \\
0 \\
\sigma \\
\infty \\
0\end{array}$ & 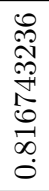 \\
\hline $2^{N}$ & $\begin{array}{l}\exists \\
\exists \\
\exists \\
\Xi \\
\Xi \\
\exists \\
0 \\
0\end{array}$ & 0 & 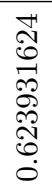 & 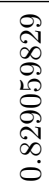 & 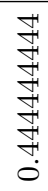 & 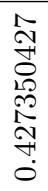 & 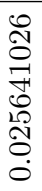 & 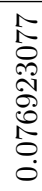 & $\neg$ \\
\hline$\underbrace{\overrightarrow{3}}$ & $\neg$ & 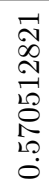 & 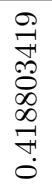 & 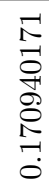 & 0 & 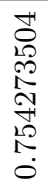 & 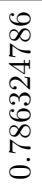 & 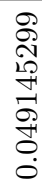 & 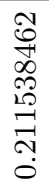 \\
\hline$\frac{a}{21}$ & 0 & 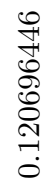 & 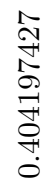 & 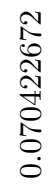 & 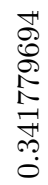 & $\begin{array}{l}\infty \\
\infty \\
1 \\
10 \\
0 \\
20 \\
10 \\
10 \\
0\end{array}$ & 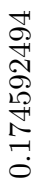 & 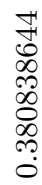 & $\neg$ \\
\hline $\mathcal{N}^{\overrightarrow{1}}$ & 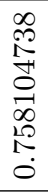 & 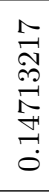 & 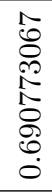 & $\begin{array}{l}7 \\
7 \\
10 \\
10 \\
1 \\
5 \\
0 \\
0 \\
0 \\
0\end{array}$ & \begin{tabular}{l}
$\infty$ \\
$\infty$ \\
$\infty$ \\
1 \\
\multirow{F}{*}{} \\
0 \\
0 \\
0 \\
0 \\
10 \\
0 \\
0
\end{tabular} & 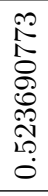 & 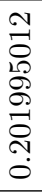 & 0 & $\neg$ \\
\hline 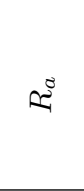 & 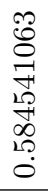 & 0 & 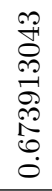 & 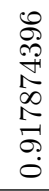 & 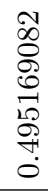 & 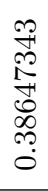 & 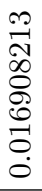 & 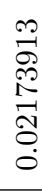 & $\neg$ \\
\hline 2 & 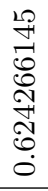 & 0 & $\begin{array}{l}\vec{N} \\
\infty \\
\infty \\
\infty \\
0 \\
0 \\
\stackrel{0}{0} \\
\dot{0}\end{array}$ & 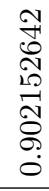 & 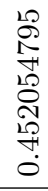 & 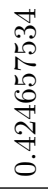 & 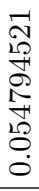 & 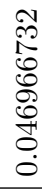 & $\neg$ \\
\hline $\begin{array}{l}\dot{0} \\
\dot{z} \\
\dot{\pi}\end{array}$ & $\neg$ & $N$ & $\infty$ & $\forall$ & ס 1 & 0 & $N$ & $\infty$ & $\sigma$ \\
\hline
\end{tabular}


Here, $x_{i}(k)$ is the value of the response $k$ for the $i$-th experiment, $\min y_{i}(k)$ is the smallest value of $y_{i}(k)$ for the $k$ th response, and $\max y_{i}(k)$ is the largest value of $y_{i}(k)$ for the $k$-th response. These normalized data corresponding to individual responses (multiple surface roughness features and MRR) have been treated as inputs to the fuzzy inference system (Fig. 4).

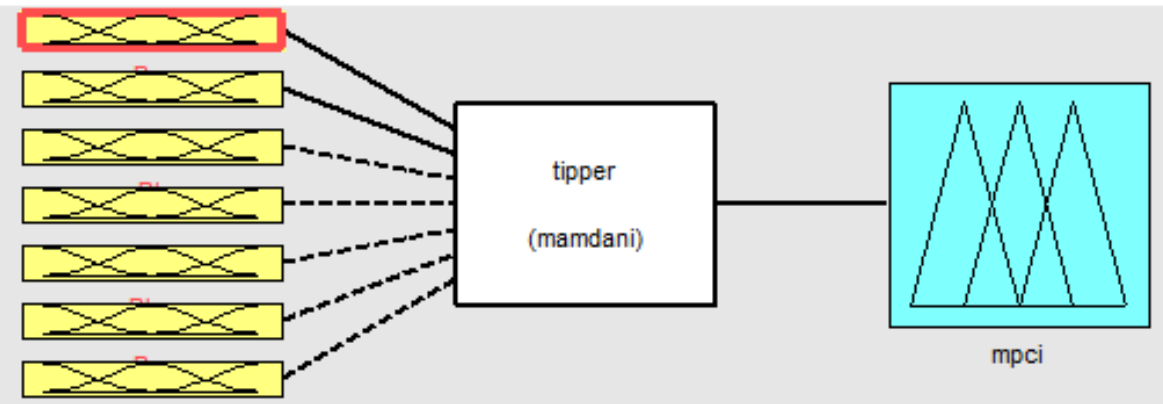

Fig. 4. Proposed fuzzy inference system (FIS)

The output of the fuzzy inference system has been defined as MPCI (Tab. 5). This Multi-Performance Characteristic Index (MPCI) has been finally optimized by using the Taguchi methodology. Higher-the-Better (HB) criterion has been used for optimizing (maximizing) the MPCI (Equation 9).

$$
\frac{S}{N}(\text { Higher-The-Better })=-10 \log \left[\frac{1}{n} \sum_{i=1}^{n}=\frac{1}{y_{i}^{2}}\right]
$$

$y_{i}$ represents the measured response data in the experiment and is the total number of trials. In calculating MPCI in the FIS system, various membership functions (MFs) (Fig. 5-11) have been assigned to the seven input variables: The selected membership functions for input variables are given below.

$$
\begin{aligned}
& R_{q}: \text { "Very High" and "High" } \\
& R_{a}: \text { "Medium", "High" and "Very High" } \\
& R_{t}: \text { "Medium" and "High" } \\
& M R R \text { : "High", "Medium" and "Low" } \\
& R_{k u}: \text { "High" and "Medium" } \\
& R_{z}: \text { "High" and "Low" } \\
& R_{s m}: \text { "High" and "Low" }
\end{aligned}
$$




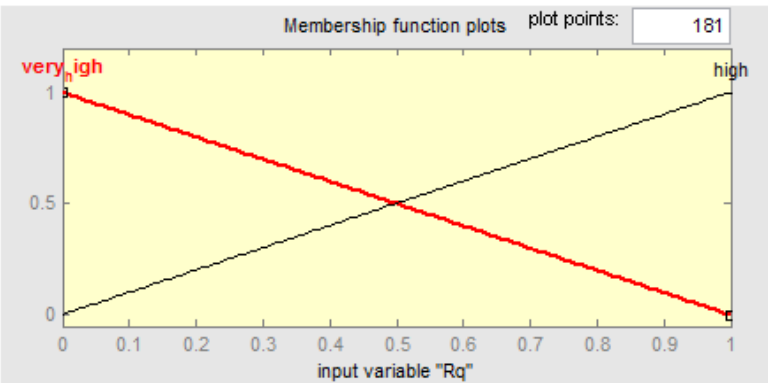

Fig. 5. MFs for $R_{q}$

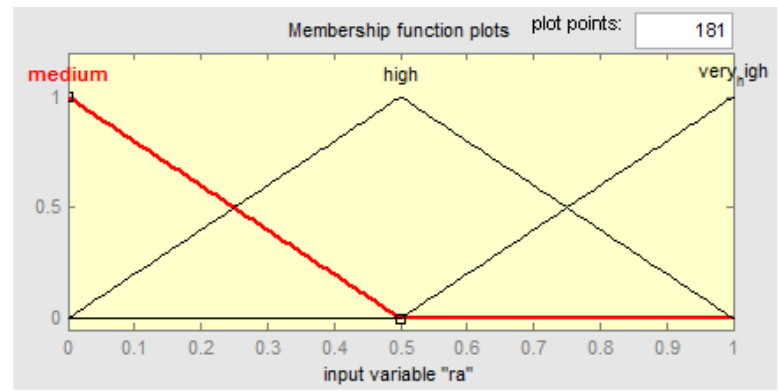

Fig. 6. $M F s$ for $R_{a}$

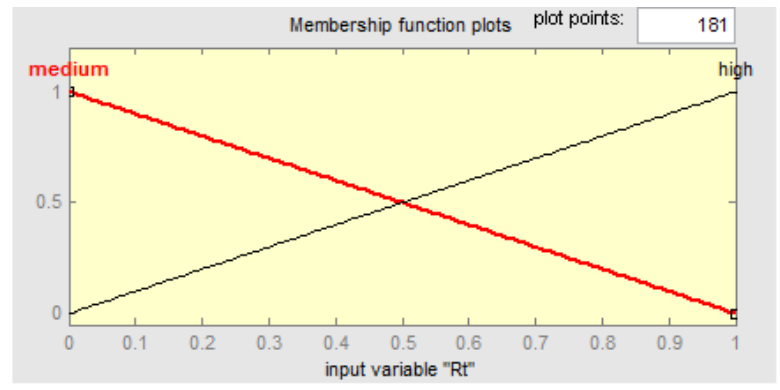

Fig. 7. MFs for $R_{t}$

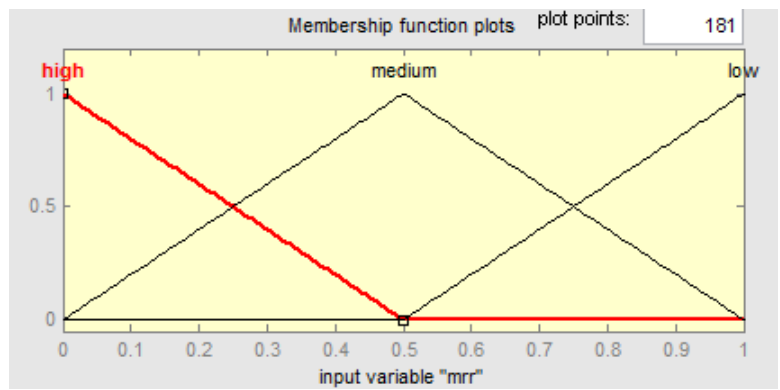

Fig. 8. MFs for $M R R$ 


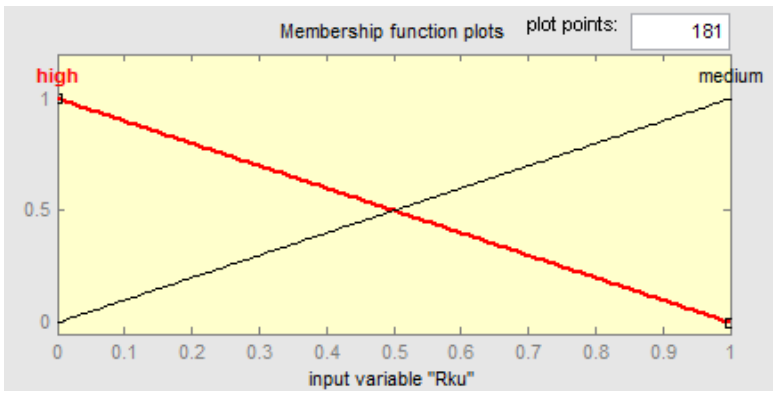

Fig. 9. MFs for $R_{k u}$

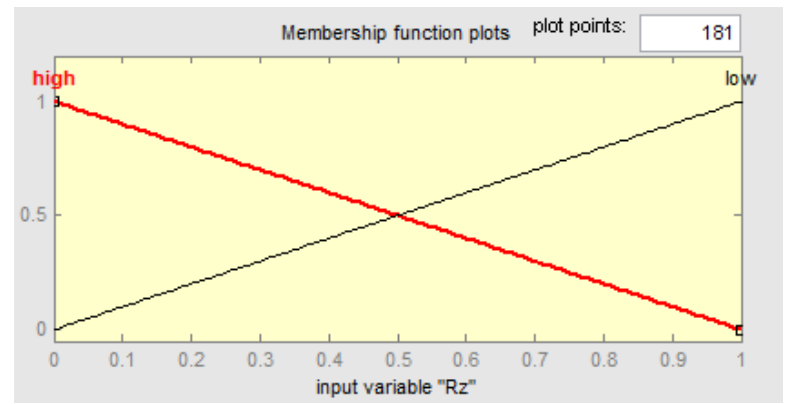

Fig. 10. MFs for $R_{z}$

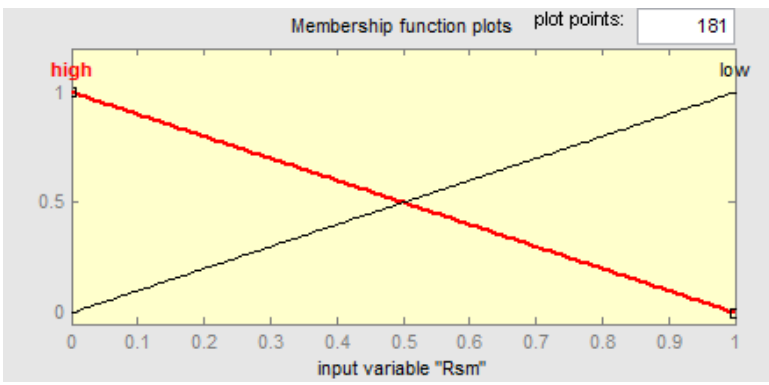

Fig. 11. MFs for $R_{s m}$

Three membership functions have been selected for MPCI: "Medium", "High", and "Very High" (Fig. 12). 100 fuzzy rules have been explored for fuzzy reasoning (Fig. 13). 


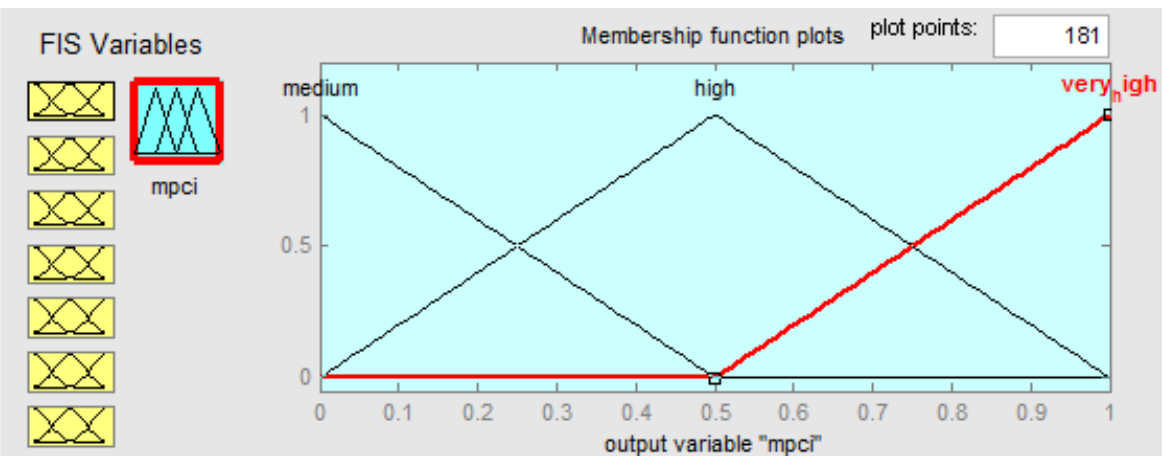

Fig. 12. MFs for $M P C I$

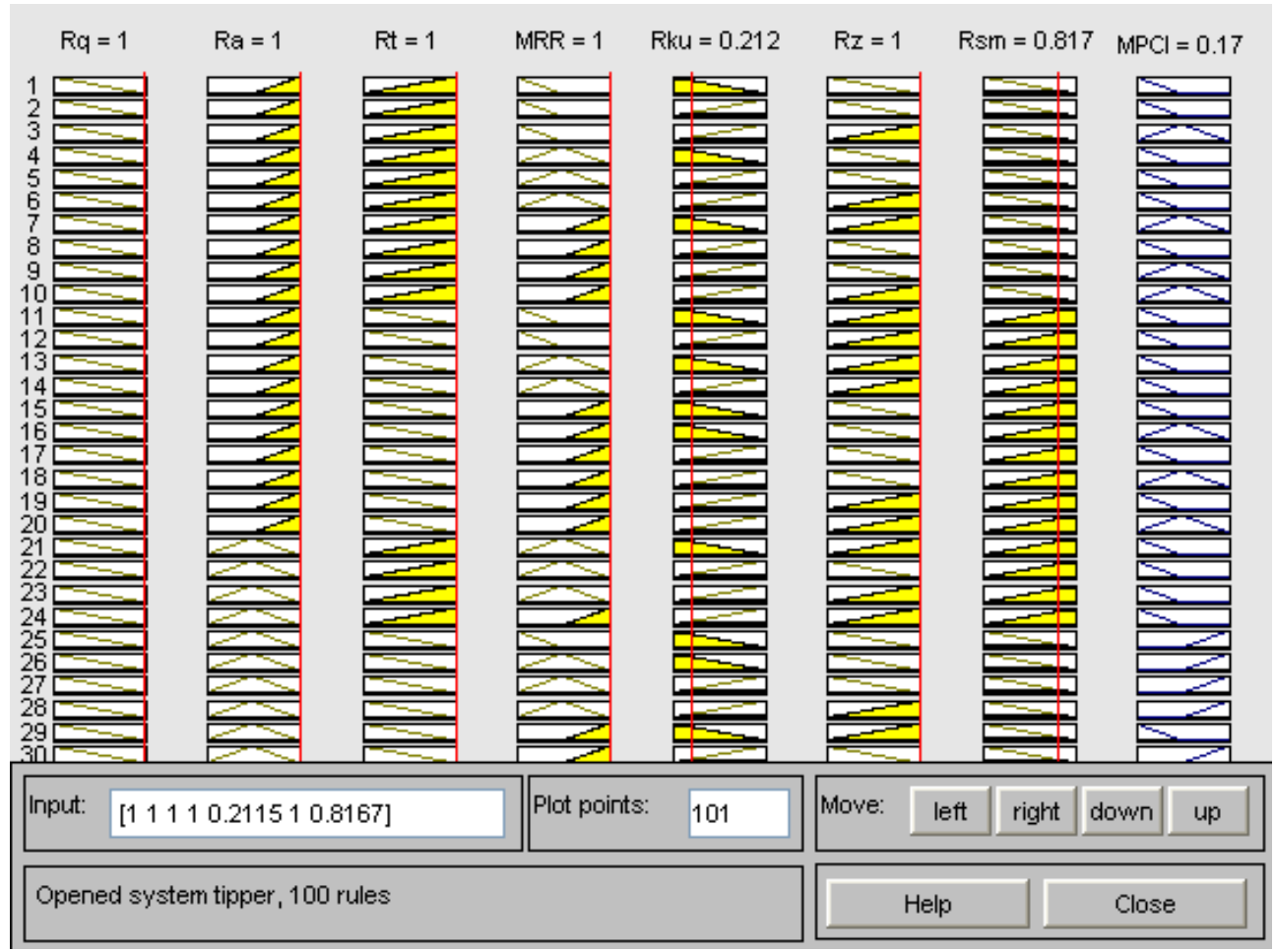

Fig. 13. Fuzzy reasoning rule base

Fuzzy based rule matrix has been shown in Appendix 1 (Sivarao et al., 2009; Ali and Zhang, 1999). Fuzzy logic converts linguistic inputs into linguistic output. Linguistic output is again converted to numeric values (MPCI) by defuzzification method. Numeric values of MPCIs have been tabulated in Table 5 with the corresponding $\mathrm{S} / \mathrm{N}$ ratio. $\mathrm{S} / \mathrm{N}$ ratios of MPCIs have been calculated using Higher-the-Better (HB) criterion. Figure 14 represents an optimal parametric combination (N1 f1 d1) where all factors are at level 1 (Tab. 1). 


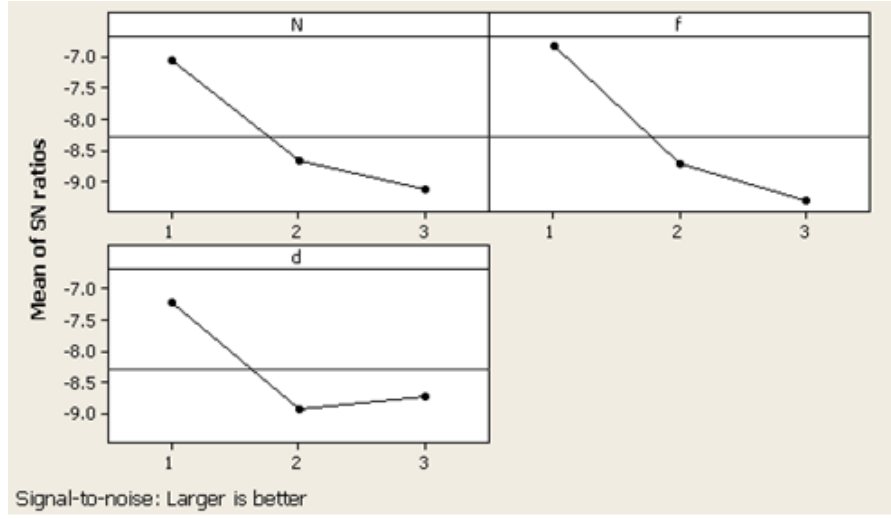

Fig. 14. Evaluation of optimal setting ( $S / N$ ratio plot for $M P C I)$

Optimal result has been validated by satisfactory confirmatory test. The predicted value of $\mathrm{S} / \mathrm{N}$ ratio of MPCI becomes -4.53347 (highest among all entries in Table 5). In the confirmatory experiment the value came -3.3367 . So, quality has improved using the said optimal setting. Table 6 represents the mean values of the $\mathrm{S} / \mathrm{N}$ ratio of MPCIs. The degree of influence of various factors on MPCI can be estimated from this table. It shows that feed rate is the most significant factor influencing MPCIs following by spindle speed and depth of cut.

Table 6. Mean value ( $S / N$ ratio of $M P C I)$ table

\begin{tabular}{|c|c|c|c|}
\hline Level & $N$ & $f$ & $d$ \\
\hline 1 & -7.053 & -6.830 & -7.226 \\
\hline 2 & -8.667 & -8.717 & -8.921 \\
\hline 3 & -9.144 & -9.317 & -8.717 \\
\hline Delta & $\mathbf{2 . 0 9 1}$ & $\mathbf{2 . 4 8 7}$ & $\mathbf{1 . 6 9 5}$ \\
\hline Rank & $\mathbf{2}$ & $\mathbf{1}$ & $\mathbf{3}$ \\
\hline \multicolumn{4}{|c}{ Delta $=$ (Max. - Min.) } \\
\hline
\end{tabular}

\section{CONCLUSIONS AND RECOMMENDATIONS}

In this study, the fuzzy rule based model has been developed using seven input variables with single output i.e. MPCI. By this way a multi-response optimization problem has been converted to an equivalent single objective optimization problem which has been further solved by the Taguchi philosophy. The proposed procedure is simple, effective in developing a robust, versatile and flexible mass production process. In the proposed model it is not required to assign individual response weights; no need to check for response correlation. FIS can efficiently take care of these aspects into its internal hierarchy thereby overcoming various limitations/assumptions of existing optimization approaches. The degree of influence of various process control 
factors can be investigated easily. Accuracy in prediction of the model analysis can be subsequently increased by assigning adequate fuzzy rules as well as by increasing the number of membership functions in the fuzzy inference system. This approach can be recommended for continuous quality improvement and off-line quality control of a process/product in any manufacturing/ production environment.

APPENDIX 1: Fuzzy rules

\begin{tabular}{|c|c|c|c|c|c|c|c|c|}
\hline Sl. No. & $\begin{array}{c}\text { If } \\
\left(R_{q}\right)\end{array}$ & $\begin{array}{l}\text { And } \\
\left(R_{a}\right)\end{array}$ & $\begin{array}{l}\text { And } \\
\left(R_{t}\right)\end{array}$ & $\begin{array}{c}\text { And } \\
(M R R)\end{array}$ & $\begin{array}{l}\text { And } \\
\left(R_{k u}\right)\end{array}$ & $\begin{array}{l}\text { And } \\
\left(R_{z}\right)\end{array}$ & $\begin{array}{c}\text { And } \\
\left(R_{s m}\right)\end{array}$ & $\begin{array}{c}\text { Then } \\
(M P C I)\end{array}$ \\
\hline 1 & \multirow{36}{*}{ 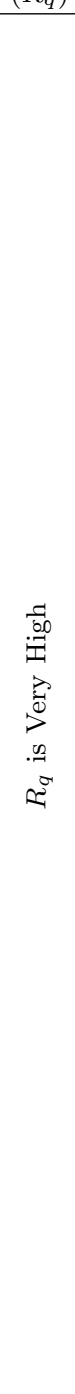 } & \multirow{20}{*}{ 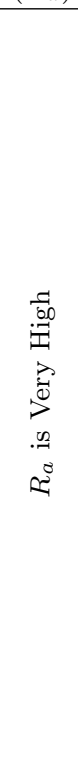 } & \multirow{10}{*}{ 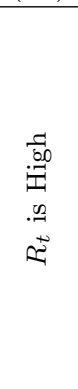 } & \multirow{3}{*}{ High } & High & High & High & Medium \\
\hline 2 & & & & & \multirow{2}{*}{ Medium } & High & High & Medium \\
\hline 3 & & & & & & Low & High & High \\
\hline 4 & & & & \multirow{3}{*}{ Medium } & High & High & High & Medium \\
\hline 5 & & & & & \multirow{2}{*}{ Medium } & High & High & Medium \\
\hline 6 & & & & & & Low & High & Medium \\
\hline 7 & & & & \multirow{4}{*}{ Low } & High & Low & High & High \\
\hline 8 & & & & & \multirow{3}{*}{ Medium } & High & High & Medium \\
\hline 9 & & & & & & High & High & High \\
\hline 10 & & & & & & Low & High & High \\
\hline 11 & & & & Hich & High & Low & Low & Medium \\
\hline 12 & & & & Hign & Medium & Low & Low & Medium \\
\hline 13 & & & & Medium & High & Low & Low & Medium \\
\hline 14 & & &.$\Xi$ & iviecurum & Medium & Low & Low & Medium \\
\hline 15 & & & ت্ّ & & & High & Low & Medium \\
\hline 16 & & & $\sum_{n}$ & & High & High & Low & High \\
\hline 17 & & & 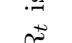 & Iон & & High & Low & Medium \\
\hline 18 & & & & LOW & & High & Low & High \\
\hline 19 & & & & & Medium & Low & Low & Medium \\
\hline 20 & & & & & & Low & Low & High \\
\hline 21 & & \multirow{11}{*}{ 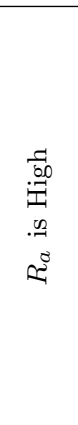 } & \multirow{4}{*}{ 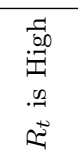 } & \multirow{3}{*}{ Medium } & High & Low & Low & Medium \\
\hline 22 & & & & & \multirow{2}{*}{ Medium } & High & Low & Medium \\
\hline 23 & & & & & & Low & Low & Medium \\
\hline 24 & & & & Low & Medium & Low & Low & Medium \\
\hline 25 & & & \multirow{7}{*}{ 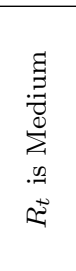 } & High & High & High & High & V. High \\
\hline 26 & & & & \multirow{3}{*}{ Medium } & High & High & High & V. High \\
\hline 27 & & & & & \multirow{2}{*}{ Medium } & High & High & V. High \\
\hline 28 & & & & & & Low & High & V. High \\
\hline 29 & & & & \multirow{3}{*}{ Low } & High & Low & High & Medium \\
\hline 30 & & & & & \multirow{2}{*}{ Medium } & High & High & V. High \\
\hline 31 & & & & & & Low & High & Medium \\
\hline 32 & & \multirow{5}{*}{ 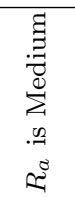 } & \multirow{5}{*}{ 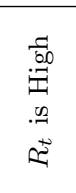 } & \multirow{5}{*}{ High } & \multirow[b]{2}{*}{ High } & Low & Low & Medium \\
\hline 33 & & & & & & Low & Low & High \\
\hline 34 & & & & & \multirow{3}{*}{ Medium } & High & Low & V. High \\
\hline 35 & & & & & & Low & Low & Medium \\
\hline 36 & & & & & & Low & Low & High \\
\hline
\end{tabular}


cont.

\begin{tabular}{|c|c|c|c|c|c|c|c|c|}
\hline Sl. No. & $\begin{array}{c}\text { If } \\
\left(R_{q}\right) \\
\end{array}$ & $\begin{array}{l}\text { And } \\
\left(R_{a}\right) \\
\end{array}$ & $\begin{array}{l}\text { And } \\
\left(R_{t}\right)\end{array}$ & $\begin{array}{c}\text { And } \\
(M R R)\end{array}$ & $\begin{array}{c}\text { And } \\
\left(R_{k u}\right)\end{array}$ & $\begin{array}{l}\text { And } \\
\left(R_{z}\right) \\
\end{array}$ & $\begin{array}{c}\text { And } \\
\left(R_{s m}\right)\end{array}$ & $\begin{array}{c}\text { Then } \\
(M P C I)\end{array}$ \\
\hline 37 & & & & \multirow{3}{*}{ Medium } & High & Low & Low & Medium \\
\hline 38 & & & & & \multirow{2}{*}{ Medium } & High & Low & Medium \\
\hline 39 & & & & & & Low & Low & Medium \\
\hline 40 & & & & \multirow{2}{*}{ Low } & \multirow{2}{*}{ Medium } & Low & Low & High \\
\hline 41 & & & & & & Low & Low & Medium \\
\hline 42 & & & \multirow{3}{*}{ 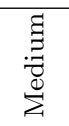 } & \multirow{3}{*}{ High } & \multirow{2}{*}{ High } & High & High & Medium \\
\hline 43 & & & & & & High & High & V. High \\
\hline 44 & & & & & \multirow{3}{*}{ Medium } & High & High & Medium \\
\hline 45 & & & \multirow{8}{*}{ 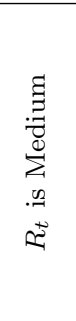 } & \multirow{2}{*}{ High } & & High & High & V. High \\
\hline 46 & & & & & & Low & High & Medium \\
\hline 47 & & & & \multirow{3}{*}{ Medium } & High & High & High & V. High \\
\hline 48 & & & & & \multirow{2}{*}{ Medium } & High & High & V. High \\
\hline 49 & & & & & & Low & High & V. High \\
\hline 50 & & & & \multirow{3}{*}{ Low } & High & Low & High & Medium \\
\hline 51 & & & & & \multirow{2}{*}{ Medium } & High & High & V. High \\
\hline 52 & & & & & & Low & High & Medium \\
\hline 53 & \multirow{27}{*}{$\begin{array}{l}\frac{\pi}{60} \\
.7 \\
.7 \\
.7 \\
2\end{array}$} & \multirow{21}{*}{ 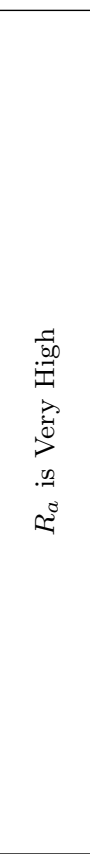 } & \multirow{10}{*}{ 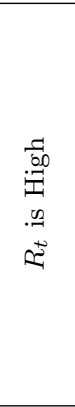 } & \multirow{3}{*}{ High } & High & High & Low & Medium \\
\hline 54 & & & & & \multirow{2}{*}{ Medium } & High & Low & Medium \\
\hline 55 & & & & & & Low & Low & Medium \\
\hline 56 & & & & \multirow{4}{*}{ Medium } & High & High & Low & Medium \\
\hline 57 & & & & & \multirow{3}{*}{ Medium } & High & Low & Medium \\
\hline 58 & & & & & & Low & Low & V. High \\
\hline 59 & & & & & & Low & Low & Medium \\
\hline 60 & & & & \multirow{3}{*}{ Low } & High & Low & Low & Medium \\
\hline 61 & & & & & \multirow{2}{*}{ Medium } & High & Low & Medium \\
\hline 62 & & & & & & Low & Low & Medium \\
\hline 63 & & & & & High & Low & High & Medium \\
\hline 64 & & & & High & & High & High & V. High \\
\hline 65 & & & & High & Medium & Low & Low & Medium \\
\hline 66 & & & & & & Low & High & Medium \\
\hline 67 & & & $\underline{\Xi}$ & & High & Low & High & Medium \\
\hline 68 & & & 苞 & Medium & & High & High & V. High \\
\hline 69 & & & $\sum_{0}$ & Medirum & Medium & Low & Low & Medium \\
\hline 70 & & & $\vec{t}$ & & & Low & High & Medium \\
\hline 71 & & & & & High & High & High & V. High \\
\hline 72 & & & & Low & Medium & High & High & V. High \\
\hline 73 & & & & & iviedium & Low & High & V. high \\
\hline 74 & & & & & High & Low & High & V. High \\
\hline 75 & & $\frac{7}{60}$ & $\frac{9}{60}$ & Medium & $\mathrm{Me}$ & High & High & V. High \\
\hline 76 & & 焉 & $\stackrel{\infty}{\infty}$ & & Me & Low & High & V. High \\
\hline 77 & & .2 &. & & High & High & High & V. High \\
\hline 78 & & 2 & टు & Low & Me & High & High & V. High \\
\hline 79 & & & & & Medium & Low & High & V. High \\
\hline
\end{tabular}


cont.

\begin{tabular}{|c|c|c|c|c|c|c|c|c|}
\hline Sl. No. & $\begin{array}{c}\text { If } \\
\left(R_{q}\right)\end{array}$ & $\begin{array}{l}\text { And } \\
\left(R_{a}\right)\end{array}$ & $\begin{array}{l}\text { And } \\
\left(R_{t}\right)\end{array}$ & $\begin{array}{c}\text { And } \\
(M R R)\end{array}$ & $\begin{array}{l}\text { And } \\
\left(R_{k u}\right)\end{array}$ & $\begin{array}{l}\text { And } \\
\left(R_{z}\right)\end{array}$ & $\begin{array}{c}\text { And } \\
\left(R_{s m}\right)\end{array}$ & $\begin{array}{c}\text { Then } \\
(M P C I)\end{array}$ \\
\hline 80 & & & & Medium & Medium & Low & Low & V. High \\
\hline 81 & & & $\mathscr{\Xi} . \Xi$ & & High & Low & Low & Medium \\
\hline 82 & & & $\stackrel{\overrightarrow{0}}{\pi}$ & Low & Medium & High & Low & V. High \\
\hline 83 & & & & & 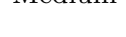 & Low & Low & Medium \\
\hline 84 & & & & & High & Low & High & V. High \\
\hline 85 & & $\Xi$ & 5 & High & Medium & High & High & V. High \\
\hline 86 & & $\stackrel{\Xi}{\mathscr{D}}$ & 凷 & & 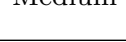 & Low & High & V. High \\
\hline 87 & & $\cong$ &.$\simeq$ & & High & Low & High & V. High \\
\hline 88 & & 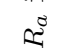 & & Medium & Medium & High & High & V. High \\
\hline 89 & & & & & & Low & High & V. High \\
\hline 90 & \multirow{11}{*}{ 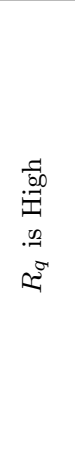 } & \multirow{11}{*}{ 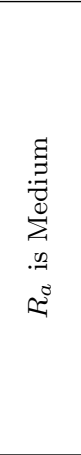 } & $\frac{9}{60}$ & \multirow{4}{*}{ Low } & High & High & High & V. High \\
\hline 91 & & & $\exists$ & & \multirow{3}{*}{ Medium } & High & High & V. High \\
\hline 92 & & &. & & & Low & High & V. High \\
\hline 93 & & & 2 & & & Low & High & Medium \\
\hline 94 & & & \multirow{7}{*}{ 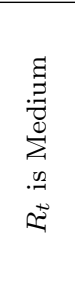 } & High & Medium & Low & Low & Medium \\
\hline 95 & & & & Medium & Medium & Low & Low & V. High \\
\hline 96 & & & & \multirow{5}{*}{ Low } & \multirow{2}{*}{ High } & Low & Low & V. High \\
\hline 97 & & & & & & Low & Low & Medium \\
\hline 98 & & & & & \multirow{3}{*}{ Medium } & High & Low & V. High \\
\hline 99 & & & & & & Low & Low & V. High \\
\hline 100 & & & & & & Low & Low & Medium \\
\hline
\end{tabular}

APPENDIX 2: Definitions of various surface roughness parameters

\section{$R_{a}$ (arithmetic average height)}

Roughness average $R_{a}$ is the arithmetic average of the absolute values of the roughness profile ordinates. $R_{a}$ is the arithmetic mean roughness value from the amounts of all profile values:

$$
R_{a}=\frac{1}{l} \int_{0}^{l}|Z(X)| d x
$$

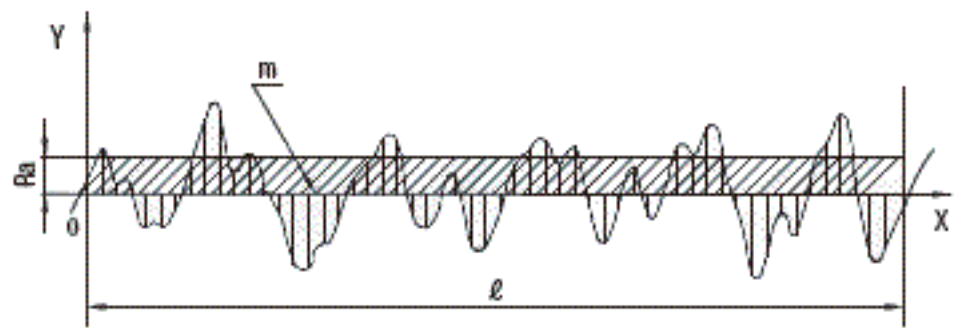




\section{$R_{q}$ (root mean square roughness)}

Root mean square (RMS) roughness $R_{q}$ is the root mean square average of the roughness profile ordinates. $R_{q}$ is more sensitive to peaks and valleys than $R_{a}$, because the amplitudes are squared.

$$
R_{q}=\sqrt{\frac{1}{l} \int_{0}^{l} Z^{2}(X)} d x
$$

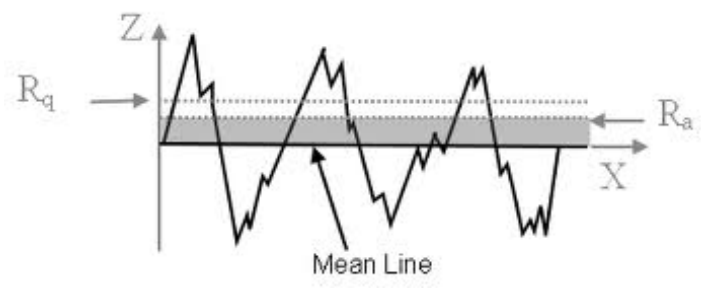

\section{$R_{z}$ (Average Maximum Height of the Profile)}

It is the mean of the distance between the highest and lowest points of five successive sample lengths of the roughness profile. It is more sensitive than $R_{a}$ to changes in surface finish, as maximum profile heights and not averages are being examined. The mean roughness depth $R_{z}$ is the mean of five roughness depths of five successive sample lengths $l$ of the surface roughness. $Z$ is the sum of the height of the highest peaks and the lowest valley depth within a sampling length. $R_{z}$ is more sensitive than $R_{a}$ to changes in surface finish as maximum profile heights and not averages are being examined:

$$
R_{z}=\frac{1}{5}\left(R_{z 1}+R_{z 2}+R_{z 3}+R_{z 4}+R_{z 5}\right)
$$

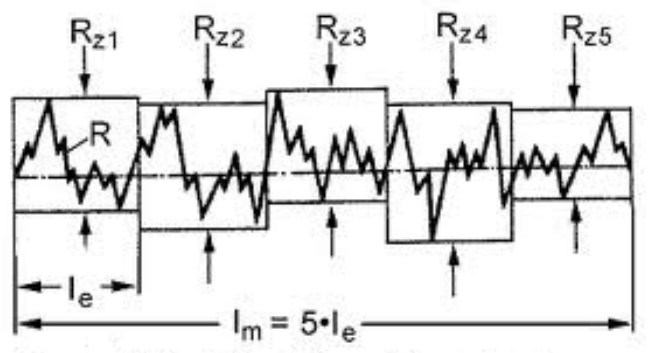

\section{$R_{t}$ (Maximum Height of Profile)}

The maximum height of the profile is the distance between the maximum peak height and the maximum valley depth from the mean line in each sampling length. $R_{z}$ is the 
mean value of the maximum peak-to-valley heights in the evaluation length. $R_{t}$ is the distance between the highest peak and the deepest valley of the profile of the total evaluation length.

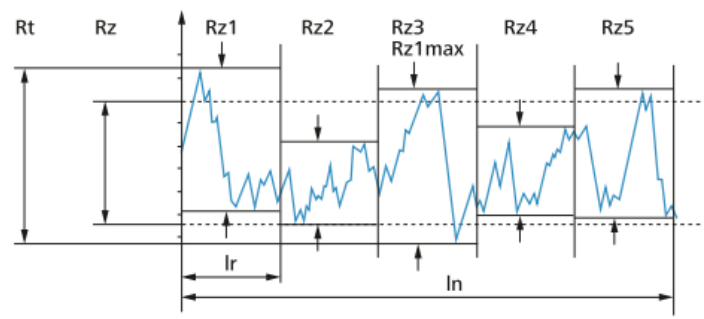

\section{$R_{s m}$ (Mean width of profile elements)}

It is the arithmetic mean value of the widths of the profile elements of the roughness profile, where a profile element is a peak and valley in the roughness profile. The units of $R_{s m}$ are micrometers or micro inches:

$$
R_{s m}=\left(\frac{1}{n} \sum_{i}^{n} S_{m i}\right)
$$

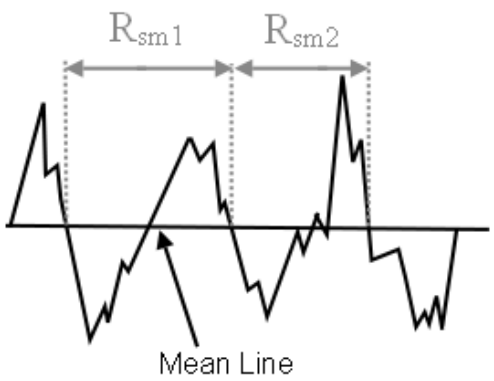

\section{$R_{k u}$ (Kurtosis of the roughness profile)}

It is the quotient of the mean quadratic value of the ordinate value $Z(x)$ he fourth power of the $P_{q}, R_{q}$, or $W_{q}$ respectively, within a sampling length. It is a measure of sharpness of the probability density function of the ordinate value:

$$
R_{k u}=\frac{1}{N R_{q}^{4}} \sum_{j=1}^{N} r_{j}^{4}
$$

\section{ACKNOWLEDGMENTS}

The authors are grateful to an anonymous referee for valuable suggestions. 


\section{REFERENCES}

Ali, Y.M., Zhang, L.C., 1999. Surface roughness prediction of ground components using a fuzzy logic approach, Journal of Materials Processing Technology, 89-90, pp. 561-568.

Bagci, E., Işık, B., 2006. Investigation of surface roughness in turning unidirectional GFRP composites by using RS methodology and ANN, International Journal of Advanced Manufacturing Technology, 31, pp. 10-17.

Basheer, A.C., Dabade, U.A, Joshi, S.S, Bhanuprasad, V.V., Gadre, V.M., 2008. Modeling of surface roughness in precision machining of metal matrix composites using ANN', Journal of Materials Processing Technology, 197, pp. 439-444.

Cox, E.A., 1992. Fuzzy Fundamentals, IEEE Spectrum, 29, pp. 58-61.

Davim, J.P., Mata, F., 2005a. Optimisation of surface roughness on turning fibre-reinforced plastics (FRPs) with diamond cutting tools, International Journal of Advanced Manufacturing Technology, 26, pp. 319-323.

Davim, J.P., Mata, F., 2005b. A new machinability index in turning fiber reinforced plastics, Journal of Materials Processing Technology, 170, pp. 436-440.

Davim, J.P., Mata F., 2007. New machinability study of glass fibre reinforced plastics using polycrystalline diamond and cemented carbide (K15) tools, Materials and Design, 28, pp. 1050-1054.

Davim, J.P., Silva, L.R., Festas, A. and Abrão, A.M., 2009. Machinability study on precision turning of PA66 polyamide with and without glass fiber reinforcing, Materials and Design, 30, pp. 228-234.

Datta, S., Bandyopadhyay, A. and Pal, P.K., 2008. Grey based Taguchi method for optimization of bead geometry in submerged arc bead-on-plate welding, International Journal of Advanced Manufacturing Technology, 39, pp. 1136-1143.

Datta, S., Nandi, G., Bandyopadhyay, A., 2009a. Application of entropy measurement technique in grey based Taguchi method for solution of correlated multiple response optimization problems: A case study in welding, Journal of Manufacturing Systems, 28, pp. 55-63.

Datta, S., Nandi, G., Bandyopadhyay, A., Pal, P.K., 2009b. Application of PCA based hybrid Taguchi method for multi-criteria optimization of submerged arc weld: A case study, International Journal of Advanced Manufacturing Technology, 45(3-4), pp. 276-286.

El-Sonbaty, I., Khashaba, U.A., Machaly, T., 2004. Factors affecting the machinability of GFR/epoxy composites, Composite Structure, 63, pp. 329-338.

Jamal, Y Seheikh-Ahmad, 2009. Machining of Polymer Composites, Springer, 2009.

Jawali, N.D., Siddeswarappa, B., Siddaramaiah, 2006. Physicomechanical Properties, Machinability, and morphological behavior of short glass fiber-reinforced nylon 6 composites, Journal of Reinforced Plastics and Composites, 25(13), pp. 1409-1418.

Karnik, S.R., Gaitonde, V.N., Mata, F., Davim, J.P., 2008. Investigative Study on Machinability Aspects of Unreinforced and Reinforced PEEK Composite Machining using ANN Model, Journal of Reinforced Plastics and Composites, 27(7), pp. 751-768.

Kumar, P., Barua, P.B., Gaindhar, J.L., 2000. Quality optimization (multi-characteristics) through Taguchi's technique and utility concept, Quality and Reliability Engineering International, 16, pp. 475-485.

Liao, Hung-Chang, 2006. Multi-response optimization using weighted principal component, International Journal of Advanced Manufacturing Technology, 27(7-8), pp. 720-725.

Lu, D., Antony, J., 2007. Optimization of multiple responses using a fuzzy-rule based inference system, International Journal of Production Research, 40(7), pp. 1613-1625.

Mendel, J.M., 1995. Fuzzy Logic Systems for Engineering: A Tutorial, IEEE Proc., 83, pp. $345-377$. 
Mohan, N.S., Ramachandra, A., Kulkarni, S.M., 2005. Influence of process parameters on cutting force and torque during drilling of glass-fiber polyester reinforced composites, Composite Structures, $\mathbf{7 1}$, pp. 407-413.

Palanikumar, K., 2007. Modeling and analysis for surface roughness in machining glass fiber reinforced plastics using response surface methodology, Materials and Design, 28, pp. 2611-2618.

Palanikumar, K., 2008. Application of Taguchi and response surface methodologies for surface roughness in machining glass fiber reinforced plastics by PCD tooling, International Journal for Advanced Manufacturing Technology, 36, pp. 19-27.

Palanikumar, K., Davim, J.P., 2008. Mathematical model to predict tool wear on the machining of glass fiber reinforced plastic composites, Materials and Design, 28, pp. 2008-2014.

Palanikumar, K., Davim, J.P., 2009. Assessment of some factors influencing tool wear on the machining of glass fiber-reinforced plastics by coated cemented carbide tools, Journal of Materials Processing Technology, 209, pp. 511-519.

Palanikumar, K., Karunamoorthy, L., Karthikeyan, R., 2006. Assessment of factors influencing surface roughness on the machining of glass fiber-reinforced polymer composites, Materials and Design, 27, pp. 862-871.

Palanikumar, K., Mata, F., Davim, J.P., 2008. Analysis of surface roughness parameters in turning of FRP tubes by PCD tool, Journal of Materials Processing Technology, 204, pp. $469-474$.

Routara, B.C., Mohanty, S.D., Datta, S., Bandyopadhyay, A., Mahapatra, S.S., 2010. Combined Quality Loss (CQL) concept in PCA based Taguchi philosophy for optimization of multiple surface quality characteristics of UNS C34000 Brass in cylindrical grinding, International Journal of Advanced Manufacturing Technology, 51, pp. 135-143.

Sahoo, P., 2005. Engineering Tribology, Prentice Hall of India, New Delhi.

Sait, A. Naveen, Aravindan, S., Haq, A. Noorul, 2008. Optimisation of machining parameters of glass-fiber-reinforced plastic (GFRP) pipes by desirability function analysis using Taguchi technique, International Journal of Advanced Manufacturing Technology, DOI 10.1007/s00170-008-1731-y (Article in Press).

Santhanakrishnan, G., Krishnamurthy, R., Malhotra, S.K., 1988. Machinability characteristics of fibre reinforced plastics composites, Journal of Mechanical Working Technology, 17, pp. 195-204.

Sivarao, Brevern, P., El-Tayeb, N.S.M., Vengkatesh, V.C., 2009. Mamdani fuzzy inference system modeling to predict surface roughness in laser machining, International Journal of Intellectual Information Technology, 2(1), pp. 12-18.

Walia, R.S., Shan, H.S., Kumar, P., 2006. Multi-response optimization of CFAAFM process through Taguchi method and utility concept, Materials and Manufacturing Processes, 21, pp. 907-914.

Yager, R.R., Filev, D.P., 1999. Essential of Fuzzy Modeling and Control, John Willey and Sons Inc., New York.

Zadeh, L.A., 1976. Fuzzy-algorithm approach to the definition of complex or imprecise concept, International Journal of Man Machine Studies, 8, pp. 249-291.

http://www.mdacomposites.org/mda/frp_def.html

http://www. acmanet.org/fgmc/abc_frp.htm 